\title{
ПРАВОВОЕ ПОЛЕ ИННОВАЦИОННОЙ ДЕЯТЕЛЬНОСТИ В ПРАКТИКЕ РАБОТЫ БИБЛИОТЕК
}

\section{LEGAL FIELD OF INNOVATION IN THE PRACTICE OF LIBRARIES}

O. Lopatina

Summary. The legal field of innovative activity of libraries is determined based on the study of regulatory legal acts of the Federal and regional levels. The analysis of publications of scientists and lawyers, reflecting the state of the legal framework for state regulation of innovation activities. Based on the content analysis of library specialists, the authors note the peculiarities of organizing and managing innovative activities in the library sphere. The problems of using legislative and regulatory documents in the practical work of libraries are outlined.

Keywords: legal field, legal relations, normative legal acts, innovative legislation, content analysis, library legislation, standardization, innovative activity of the library.

\author{
Лопатина Ольга Александровна \\ К.n.н., профессор, Хабаровский государственный \\ институт культуры \\ Lopatina-OA@Rambler.ru
}

Аннотация. Определено правовое поле инновационной деятельности библиотек на основе изучения нормативных правовых актов федерального и регионального уровня. Проведен анализ публикаций ученых и юристов, отражающий вопросы состояния нормативно-правовой базы по государственному регулированию инновационной деятельности. На основе контент-анализа специалистов библиотечного дела отмечены особенности организации и управления инновационной деятельностью в библиотечной сфере. Обозначены проблемы использования законодательных и нормативных документов в практической работе библиотек.

Ключевые слова: правовое поле, правоотношения, нормативные правовые акты, инновационное законодательство, контент-анализ, библиотечное законодательство, стандартизация, инновационная деятельность библиотеки.

гулирующие различные направления ее деятельности, на что указывает Ф3 «О библиотечном деле» (ст. 2).

Поступательное развитие законодательства во всех сферах народного хозяйства создало новую ситуацию для развития библиотечно-информационной деятельности и обусловило ее изменение. В этих условиях руководителям и специалистам библиотек приходится постоянно осваивать и осмысливать новые нормы права, содержащиеся в различных отраслях права, в том числе в гражданском, предпринимательском, бюджетном, налоговом, трудовом и т.п.

С целью определения правового поля инновационной деятельности библиотек нами были изучены основные нормативные правовые акты, регулирующие библиотечно-информационную деятельность как субъекта правовых отношений. Знание системы правовых и нормативных документов, по нашему мнению, позволит юридически грамотно выстраивать работу библиотек по расширению и уточнению терминологического аппарата, формированию системы управления инновационной деятельностью библиотеки, по работе с кадрами, по повышению качества библиотечно-информационных продуктов и услуг и т.п. Теория библиотечной инноватики в настоящее время достаточно глубоко разработана в отечественном библиотековедении, однако правовые документы, непосредственно касающиеся инновацион- 
ной деятельности в отрасли культуры, в настоящее время отсутствуют, что осложняет единство подходов в критериях оценки инноваций в деятельности российских библиотек.

Правовые отношения субъектов и объектов инновационной деятельности регулируются нормативными правовыми актами, в которых обозначены основные категории и понятия в этой области, освещаются вопросы государственной политики, формы поддержки, формирование инфраструктуры, обозначены механизмы и инструменты инновационной деятельности и т.п. Нами были отобрано более 120 нормативно-правовых документов, имеющих прямое или косвенное отношение к законодательному регулированию инновационной деятельности библиотеки.

Первым значимым документом в области инновационной деятельности специалисты считают постановление Правительства РФ «О Концепции инновационной политики Российской Федерации на 1998-2000 годы» от 24 июля 1998 г.

Федеральный закон «О науке и государственной научно-технической политике» от 23 августа 1996 г. № 127-Ф3 стал первым нормативным правовым актом, в котором даны определения основным категориям инновационной деятельности: инновации, инновационная инфраструктура, инновационная деятельность и др.

Большую роль в развитии инновационного законодательства сыграл Модельный закон «Об инновационной деятельности», утвержденный Постановлением Межпарламентской Ассамблеи стран СНГ от 16 ноября 2006 г. № 27-16. В Законе представлены основные аспекты инновационной деятельности, что в дальнейшем послужило ориентиром для развития инновационного законодательства в странах СНГ.

В марте 1999 г. в Государственную Думу впервые был внесен проект Федерального закона «Об инновационной деятельности и о государственной инновационной политике», предлагавший введение и регулирование на законодательном уровне нового института «инноваций». Однако законопроект был отклонен Президентом РФ. Среди основных аргументов отклонения было отсутствие в Законе четкого определения предмета правового регулирования - инновационной деятельности. В дальнейшем на утверждение Государственной Думы неоднократно вносились законопроекты инновационной деятельности. Сложность разработки документа объясняется многими причинами, в том числе и тем, что спектр направлений нормативно-правового обеспечения инновационной деятельности очень широк. Он охватывает вопросы государственного регулирования, правоотношения между участниками инновационного процесса, финансовое и кадровое обеспечение, охрану объектов интеллектуальной собственности, понятийный аппарат и т.п.

В настоящее время ведется разработка н обсуждение на различных площадках проекта Федерального закона «О научной, научно-технической и инновационной деятельности в Российской Федерации». Официальной основой для разработки данного федерального закона можно считать не только имеющийся законодательный массив в этой сфере, но и Концепцию проекта Федерального закона «О научной, научно-технической и инновационной деятельности в Российской Федерации» (2019 г.).

Векторами развития инновационной деятельности библиотек стали нормативные правовые акты программного и декларативного характера:

- Стратегии развития науки и инноваций в Российской Федерации на период до 2015 г. (утв. Межведомственной комиссией по научно-инновационной политике от 15 февраля 2006 г.);

- Концепция долгосрочного социально-экономического развития Российской Федерации на период до 2020 г. (утв. распоряжением Правительства РФ от 17 ноября 2008 г.);

- Стратегия инновационного развития Российской Федерации на период до 2020 года, (утв. распоряжением Правительства РФ от 8 декабря 2011 г.);

- Стратегия государственной культурной политики на период до 2030 года (утв. распоряжением Правительства РФ от 29 февраля 2016 г.);

- О национальных целях и стратегических задачах развития Российской Федерации на период до 2024 года (Указ Президента РФ от 7 мая 2018 г.);

- Концепция модернизации муниципальных библиотек Российской Федерации на основе модельного стандарта деятельности общедоступной библиотеки (утв. Минкультуры России 13 марта 2019 г.) и др.

Структуризация массива более чем 150 публикаций во времени (2001-2020 гг.) дала возможность выявить основные проблемы законодательного обеспечения инновационной деятельности в условиях современной реальности. Состояние и тенденции развития инновационного законодательства активно обсуждаются учеными и юристами в области экономики и права, преподавателями высшей школы, предпринимателями различных отраслей экономики, руководителями организаций и т.д. Массив выявленных публикаций включает вопросы государственного регулирования инновационной деятельности, организации и управления инновационной деятельностью в библиотечных организациях, 
состояние и тенденции развития инновационного законодательства в сфере культуры, в том числе в библиотечно-информационной деятельности.

Анализ публикаций по государственному регулированию инновационной деятельности позволил выявить основные тематические аспекты, это теория инновационного права, состояние и перспективы развития законодательства, система государственного регулирования, управление инновационной деятельностью в организации; проблемы разработки законопроекта об инновационной деятельности; соотношение научной и инновационной деятельности, юридическое толкование основных категорий инновационной деятельности и др.

Как полагает доктор юридических наук, специалист в области инновационного права Т.В. Ефимцева, переход к инновационной экономике невозможен без определения места инновационного права в системе российского права. Поскольку в юридической науке под предметом правового регулирования отрасли или института права понимаются общественные отношения, регулируемые нормами данной отрасли, необходимо прежде всего, считает автор, определить предмет инновационного права, т.е. установить, какие нормы и возникающие на основе их применения отношения являются инновационно-правовыми, найти ту основу, которая объединяет эти нормы и отношения в единый институт права, установить характерные черты инновационно-правовых норм и отношений, отличающие их от норм и отношений других институтов права.

По мнению Т.В. Ефимцевой, предметом инновационного права, являются три группы общественных отношений, составляющих определенное единство. Это инновационные отношения, иные отношения, связанные с инновационными отношениями и отношениями по государственному воздействию на инновационную деятельность. Причем первые две группы отношений являются горизонтальными по своей структуре, поскольку возникают между равноправными и независимыми друг от друга участниками, а третья группа представляет собой отношения по вертикали [5, с. 127-131].

А.И. Бексултанова, анализируя реализацию государственной политики в области инновационной деятельности, обращает внимание на такие формы законодательной поддержки государством инновационной деятельности, как финансовая, информационная, имущественная, а также поддержка в образовательной сфеpe [1].

Наибольшее количество публикаций посвящено формированию национальной инновационной системы, основным механизмам реализации государственной инновационной политики, созданию благоприятного инвестиционного климата для финансирования инновационной деятельности и т.п.

Мнения многих авторов сводятся к тому, что существующие нормативные правовые акты Российской Федерации в сфере инноваций пока не в полной мере соответствуют целям экономической модернизации и инновационного развития страны. До сих пор в России нет федерального закона об инновационной деятельности, что не позволяет процессу формирования национальной инновационной системы развиваться более эффективно. Большинство федеральных законов отражают лишь отдельные аспекты правоотношений инновационной деятельности, так как регулируют и стимулируют деятельность в отдельных отраслях национальной экономики и практически не включают правоотношения в отрасли культуры.

К этому следует добавить, что отсутствие общей законодательной платформы ставит регионы перед необходимостью самостоятельно разрабатывать документы в области инновационной деятельности, что вносит разнобой в целостность системы государственного регулирования данного законодательного направления.

И.Ю. Загоруйко акцентирует внимание на том, что разработкой отдельных аспектов инновационного законодательства занимаются различные ведомства, организации, группы; имеется заметный дефицит квалифицированных специалистов, обладающих необходимыми теоретическими знаниями и практическим опытом работы в инновационной сфере, существуют проблемы с понятийным аппаратом. Отсутствие базового инновационного законодательства существенным образом тормозит развитие региональной инновационной нормативно-правовой базы, и как следствие формирование благоприятного инновационного климата в субъектах РФ. Как полагает автор, можно утверждать, что в конечном итоге подобное состояние дел может привести к фрагментарности законодательства, когда отдельные элементы национальной инновационной системы будут достаточно развиты, а другие важные составные части окажутся вне правового поля и соответственно без необходимой государственной поддержки [6].

Анализ массива публикаций, отражающих вопросы организации и управления инновационной деятельности библиотек обозначил такие тематические аспекты как развитие теории библиотечной инноватики, в том числе, совершенствование терминологии; формирование библиотечной инновационной политики в контексте модернизации всех направлений библиотечно-информационной деятельности; развитие инновационного 
менеджмента библиотеки, активизацию инновационной деятельности методических служб и др.

Наибольший вклад в вопросы управления и организации инновационной деятельности в библиотеках внесли С.А. Басов, А. Н. Ванеев, Е.Н. Гусева, Е.Ю. Качанова, В.К. Клюев, Т.Я. Кузнецова, С. Г. Матлина, В.А. Минкина, Н.С. Редькина, Э.Р. Сукиасян, Н.Т. Чуприна и другие исследователи.

Обзор публикаций свидетельствует, что инновационная деятельность библиотек за последние двадцать лет достаточно глубоко изучена, теоретически и практически проработана.

Ведущим стимулом развития инноваций в библиотечной сфере по мнению многих специалистов стала модернизация в сфере культуры в т.ч. и в библиотечной отрасли. Нельзя не согласиться с Т.Я. Кузнецовой, что, пройденный российскими библиотеками путь модернизационного развития, позволяет заключить, что наряду со многими кардинальными изменениями, смысловое ядро модернизации включает в себя и инновационные преобразования всех функциональных направлений библиотечной деятельности [9].

В качестве лидера инновационных преобразований, по мнению специалистов выступает методическая служба. Как полагает Е.Ю. Качанова, ускоренные темпы технологического обновления библиотек требуют от сотрудников методических служб иного отношения к вопросам реализации инноваций, ставят их перед необходимостью решения задач реорганизации научно-исследовательской деятельности, обучения библиотечных сотрудников методикам исследовательского труда, создания корпоративного «банка идей библиотечных инноваций», развития посреднической деятельности, позволяющей библиотекам находить партнеров для решения инновационных задач и т.п. [8, с. 193]

Управление и организация инновационных процессов практически реализуется в инновационном менеджменте, который нацелен на создание необходимых условий для повышения эффективности инноваций, внедрения конкурентоспособной продукции и технологии. Как и в других сферах общественной практики, инновационный менеджмент библиотечных изменений рассматривается как особая организационно-управленческая деятельность, направленная на получение результатов библиотечного развития путем использования инноваций, а также как значимое направление стратегического управления библиотекой. Как стратегическое направление инновационный менеджмент определяет цели, масштабы и объекты изменений, возможности разработки новшеств, осуществления нововведений и использова- ния инноваций. В силу такого назначения, в нем главное внимание уделяется выработке инновационной политики, стратегии инноваций и мер, направленных на их реализацию [7, с. 58].

Е.Н.Гусева, анализируя развитие инновационной деятельности в российских библиотеках в динамике за 2000-2010 гг., приходит к выводу, что в первый период с 2000-2005 гг. большинство материалов было посвящено вопросам обоснования подходов к инновациям и новым информационным технологиям в деятельности библиотек, особое внимание уделялось новым формам деятельности библиотек (в т.ч. и на основе ИКТ). Все это находилось в русле общественных изменений того периода, который можно по мнению автора, обозначить как период «тотальной цифровизации» всей страны. Во второй половине периода (2006-2010 гг.) появились статьи философско-концептуального характера, исследующие феномен инноваций в контексте общекультурного развития общества и работы не только о применении новых технологий, но и о новых услугах и формах деятельности библиотек, а также о путях дальнейшего развития библиотек и проблемах их позиционирования в непрерывно меняющемся обществе. Интересно и то, подчеркивает Е.Н. Гусева, что специалисты стали представлять результаты неких научных исследований по вопросам инноватики как в теоретическом, так и в управленческом аспектах. Автор считает, что одним из самых главных и значимых результатов будет построение методологии и методики управления инновационной деятельностью в библиотечно-информационной деятельности, а возможно, и во всей социально-культурной сфере, потому что инновация - это, в первую очередь, эффективное управление [4].

Продолжая анализировать развитие инновационной деятельности в библиотечной сфере, в период с 2010 и по настоящее время можно утверждать, что его отличительной особенностью является активизация стандартизации библиотечной деятельности, включающей формирование нормативных требований к современной библиотеке, к технологическим процессам ее деятельности и управлению ими, терминологическому аппарату; качеству продукции, работ и услуг в соответствии с уровнем развития библиотечной науки, техники и технологии и т.п.

Анализ научных публикаций, отражающих вопросы инновационного законодательства в библиотечной сфере показал, что тематика публикаций в основном посвящена инновационной библиотечной политике, модернизации системы управления, реформированию библиотечного законодательства, стандартизации деятельности библиотек, проблемам реализация законодательства об интеллектуальной собственности и др. 
В контексте развития государственной культурной политики Е.Н.Гусева определяет правовое поле инновационной библиотечной деятельности. Важнейшим документом, определяющим развитие культуры и не имеющим аналогов в постсоветской России, Е.Н. Гусева считает «Основы государственной культурной политики», введённые в действие Указом Президента Российской Федерации от 24 декабря 2014 г. № 808. Автор подчеркивает, что впервые в документе такого высокого уровня государственная культурная политика признана неотъемлемой частью стратегии национальной безопасности Российской Федерации. Как полагает автор, это базовый документ для разработки и совершенствования законодательных и иных нормативных правовых актов, регулирующих процессы культурного развития в Российской Федерации, а также государственных и муниципальных программ [3].

Большое внимание в документальном потоке уделяется реформированию основных законов о культуре, в том числе и о библиотечном деле, что связано с вступлением в силу новых федеральных законов, отдельные положения которых относятся и к библиотечному делу. Дополнения и изменения в главном Федеральном законе РФ «О библиотечном деле» касаются терминологического аппарата, в частности понятий «библиотека», «национальный библиотечный фонд», «книжные памятники»; организации взаимодействия библиотек, статуса центральной и межпоселенческой библиотеки; порядка обслуживания особых групп пользователей; создания государственной информационной системы «Национальная электронная библиотека»; вопросов подготовки и переподготовки библиотечных кадров и др.

Дополнения и изменения внесены практически в каждую статью Федерального закона «Об обязательном экземпляре документов», в первую очередь это касается целей формирования системы обязательного экземпляра, формирования обязательного экземпляра федерального, регионального и муниципального уровней, доставки обязательного экземпляра документов, в том числе, выполненных на различных носителях и т.п.

Закон Российской Федерации «Основы Законодательства Российской Федерации о культуре» также претерпел значительные изменения. Особо следует отметить, разграничение и уточнение полномочий федеральных органов государственной власти, органов государственной власти субъектов Российской Федерации и органов местного самоуправления в области культуры (Раздел VII), а также введение статьи «Независимая оценка качества условий оказания услуг организациями культуры (ст. 36.1).
Однако особое внимание авторы публикаций, уделяют стандартизации библиотечной деятельности. Это модельные стандарты, профессиональные стандарты, ГОСТЫ Р по инновационному менеджменту, система стандартов ISO, стандарты СИБИД. Это и понятно, только за последние пять лет в действие вступило более 10 стандартов СИБИД, содержащих определения основных терминов, правила, характеристики отдельных процессов библиотечно-информационной деятельности. В частности, введены в действие ГОСТ Р 7.0.-2018 «Книжные памятники. Общие требования», ГОСТ Р 7.0.94-2015 «Комплектование библиотеки документами. Термины и определения»; ГОСТ Р 7.0.103-2018 «Библиотечно-информационное обслуживание. Термины и определения» и др.

Нормативно-правовым ориентиром адаптации деятельности библиотеки к новым социально-экономическим условиях стали модельные стандарты деятельности библиотеки (2008, 2014 гг.). Логическим продолжением модельных стандартов является разработка «Концепции модернизации муниципальных библиотек Российской Федерации на основе модельного стандарта деятельности общедоступной библиотеки» (2019 г.).

Инновационная продукция не может существовать без разработки и принятия документов в области стандартизации, так как без установления норм и правил невозможно провести необходимые для внедрения новых технологий испытания и измерения, организовать производство, оценить соответствие продукции (услуги) установленным требованиям нормативной документации с целью выхода на рынок, а также применять новую продукцию. Стандартизация, по мнению Е.Н.Гусевой, может выступать в качестве некого ускорителя продвижения инноваций, позволяя обеспечить совместимость и безопасность продукции, сосредоточение инвестиций и ресурсов на важных инновационных направлениях и задавать общее направление инноваций в библиотеках. Автором также представлена характеристика ГОСТов по инновационному менеджменту, их особенностью по ее мнению, является то, что они, по сути, представляют собой некие методические рекомендации по внедрению, формированию, развитию и использованию системы управления, направленной на развитие инновационно-ориентированной организации, управленческая система которой настроена на то, что в современном менеджменте называется управление изменениями [2].

В общем потоке публикаций большое место занимают работы по интеллектуальной собственности применительно к практике работы библиотек. Проблематика публикаций включает рассмотрение таких вопросов как объекты и субъекты авторского права в библиотеках, правоотношения публичных библиотек в условиях дей- 
ствия части IV Части Гражданского кодекса РФ, проблемы открытого доступа к научным знаниям и др.

Таким образом, исследование законодательного обеспечения инновационной деятельности позволило определить правовое поле нормативных правовых актов, систему правоотношений в практике работы библиотек. Следует отметить, что спектр законодательства, отражающего те или иные направления инновационной деятельности достаточно широк и не может быть пол- ностью отражен в рамках одной статьи. Тем не менее, главный вывод, который можно сделать, изучив нормативно-правовую базу документов и массив публикаций - данная проблема требует дальнейшего изучения, разработки терминологии и нормативов инновационной деятельности библиотек. По нашему мнению, необходимо активизировать работу по созданию стратегических документов, локальных актов библиотеки по инновационной деятельности, правовую подготовку библиотечных кадров в этом направлении и т.п.

\section{ЛИТЕРАТУРА}

1. Бексултанова А. И. Реализация государственной политики в инновационной деятельности / А. И. Бексултанова, А. Н. Бексултанова, Ш. К. Кутаев // Россия: тенденции и перспективы развития. — 2019.- - С. 498-500.

2. Гусева Е.Н. ГОСТы, обеспечивающие инновационную деятельность: вопросы применения в библиотеках [Электронный документ] (дата обращения: 24.04.2020).

3. Гусева Е. Н. Законодательное обеспечение государственной культурной политики в библиотечной отрасли: новеллы 2016 года; тенденции 2017 года // Научные и технические библиотеки.-2018. - № 1.—C. 7-18.

4. Гусева Е. Н. Инновационное развитие библиотечной сферы: аналитико-статистический обзор // Научные и технические библиотеки. 一 2011. — № 12. C. $23-40$

5. Ефимцева Т. В. Понятие инновационного права // Современные проблемы науки и образования.— 2010. — № 1— С. 127-131.

6. Загоруйко И. Ю. Правовое регулирование федеральной инновационной политики государства и тенденции ее развития // Вестник Пермского университета. Юридические науки. - 2012.—Вып. 2.- С. 58.

7. Качанова Е. Ю. Библиотечная инноватика как теория изменений: Монография. - Хабаровск, 2002. - 155 с.

8. Качанова, Е. Ю. Инновационно-методическая работа библиотек: учеб. пособие / Е.Ю Качанова; ХГИИК; науч. ред. А. Н. Ванеев.— Санкт-Петербург: Профессия, 2007.-С. 193.

9. Кузнецова Т. Я. Модернизация библиотек и их инновационные социальные практики: опыт системного анализа // Вестник МГУКИ.— 2018. — № 5 (85). C. 81-92. 